\title{
A educação de surdos em Portugal: o sistema bilíngue, o currículo e a docência no ensino da Língua Gestual Portuguesa
}

The education of the deaf in Portugal: the bilingual system, the curriculum and teaching in the teaching of the Portuguese Sign Language

La educación de las personas sordas en Portugal: el sistema bilingue, el currículo y la enseñanza en la enseñanza de la Lengua de Signos

Portuguesa

Veronica Lima da Fonseca Almeida

Doutoranda na Universidade do Porto, Porto, Portugal.

veronicalfa@gmail.com

ORCID - https://orcid.org/0000-0002-5331-7736

Henrique Malheiro Vaz

Professor doutor na Universidade do Porto, Porto, Portugal.

henrique@fpce.up.pt

ORCID - http://orcid.org/0000-0002-9061-0878

Isabel Sofia Calvário Correia

Professora doutora no Instituto Politécnico de Coimbra, Coimbra, Portugal.

icorreia@esec.pt

ORCID - http://orcid.or/ 0000-0002-1798-2165

Recebido em 18 de novembro de 2018

Aprovado em 4 de novembro de 2019

Publicado em 12 de dezembro de 2019

\section{RESUMO}

As políticas internacionais são diretrizes presentes na constituição do modelo atual de educação de surdos, em que a língua surge como um direito no que diz respeito ao acesso à educação. Portugal segue este propósito na política educativa inclusiva bilíngue explícito no Programa curricular de Língua Gestual Portuguesa (LGP). Com o objetivo de discutir o ensino da língua gestual na educação de surdos no ensino formal, constatou-se no currículo e na prática de ensino da LGP, a importância do professor surdo como um marcador cultural e linguístico. A metodologia qualitativa foi desenvolvida por análise documental nos Programas Curriculares de Língua Gestual Portuguesa na Educação Préescolar e Ensino Básico e no Ensino Secundário, e num estudo de caso realizado, em 2018, numa Escola de Referência em Educação Bilíngue de Alunos Surdos (EREBAS) com dados empíricos de entrevistas, com cinco professores surdos e observações nas aulas de LGP no ensino básico, na cidade do Porto, em Portugal. Constatou-se que, na constituição do campo da educação de surdos adotou-se a cultura surda na política inclusiva bilingue o que implicou na sistematização de mecanismos orientadores no currículo de forma a responder às necessidades do cenário político internacional e local. 
http://dx.doi.org/10.5902/1984686X34853

Considerou-se que a língua das pessoas surdas surge com o principal intuito de garantir a igualdade de oportunidade no acesso à educação, em que a integração do docente surdo visou fundamentar a prática de ensino, contudo, inicialmente, este não era visto como professor.

Palavras-chave: Sistema bilíngue; Docente surdo; Currículo de LGP.

\section{ABSTRACT}

International policies are guidelines in the constitution of the current deaf education, in which language emerges as a right in access to education. Portugal follows this purpose in the bilingual inclusive educational policy explicit in the Portuguese Sign Language Curriculum Program (LGP). In order to discuss sign language teaching for deaf students in formal education, it was evidenced in the curriculum and, in practice of the teaching of the LGP, the importance of the deaf teacher as cultural and linguistic marker. The qualitative methodology was developed by document analysis in the Portuguese Sign Language Curriculum Programs of Preschool and Basic Education and in Secondary Education as well as through a case study carried out in 2018 in a bilingual education Reference School of deaf students (EREBAS). It was used empirical data from interviews with five deaf teachers, and observations in the LGP classes in elementary school in the city of Oporto, Portugal. It was found that, in the constitution of the field of deaf education, deaf culture was adopted in the bilingual inclusive policy, which implied the systematization of guiding mechanisms in the curriculum to meet the needs of the international and local political scenario. It was considered that the language of deaf people arises with the main purpose for equal opportunity in access to education, in which the integration of deaf teachers aimed to substantiate the teaching practice but did not initially integrate it as a teacher in the educational area.

Keywords: Bilingual system; Deaf teacher; LGP curriculum.

\section{RESUMEN}

Las políticas internacionales son directrices presentes en la constitución del modelo actual de educación para sordos, en el que el idioma emerge como un derecho con respecto al acceso a la educación. Portugal sigue este propósito en la política educativa inclusiva bilingue explícita en el Currículo portugués de Lengua de Signos (LGP). Con el fin de discutir la enseñanza de la lengua de signos en la educación de las personas sordas en la educación formal, se encontró en el currículo y en la práctica docente de LGP, la importancia de los profesores sordos como marcador cultural y linguístico. La metodología cualitativa fue desarrollada por el análisis documental en los Programas Curriculares de Lengua de Signos Portuguesa en Educación Preescolar y Educación Primaria y Educación Secundaria, y en un estudio de caso realizado, en 2018, en una Escuela de Referencia en Educación Bilinguista de Estudiantes Sordos (EREBAS) con datos empíricos de entrevistas, con cinco profesores sordos y observaciones en clases LGP en primaria, en la ciudad de Oporto, Portugal. Se encontró que, en la constitución del campo de la educación sorda, se adoptó la cultura sorda en la política bilingue inclusiva, que implicaba la sistematización de los mecanismos de orientación en el plan de estudios para responder a las necesidades del escenario político internacionales y locales. Se consideró que el lenguaje de las personas sordas aparece con el objetivo principal de garantizar la 
igualdad de oportunidades en el acceso a la educación, en la que la integración de los profesores sordos tenía como objetivo fundamentar la práctica docente, sin embargo, inicialmente, no se consideraba Profesor.

Palabras clave: Sistema bilingue; Maestro sordo; Currículo LGP.

\title{
Introdução e Metodologia
}

$\mathrm{Na}$ atualidade, as políticas internacionais apresentam diretrizes que orientam a nível internacional e nacional a educação de pessoas surdas. Neste contexto, ao olhar a constituição da educação de surdos ligada às políticas globais, torna-se fulcral compreender as alterações no terreno social local, o seu impacto na organização do ensino na escola e os elementos que não se tornaram, simultaneamente, parte integrante deste processo. Perante esta situação, a língua das pessoas surdas é parte integrante da educação de surdos para igualdade de oportunidades no acesso à educação. Esta configuração é seguida na política educativa inclusiva bilingue em Portugal, visível nos discursos legais que oficializam as orientações educativas no que concerne à educação de surdos.

\begin{abstract}
O programa curricular da disciplina de Língua Gestual Portuguesa (LGP) surge com o principal propósito de pôr em prática os princípios legais que defendem a sua utilização para a igualdade de oportunidades, no acesso à educação. Esta língua deve ser reconhecida e dignificada pelo seu real estatuto, enquanto primeira língua da Comunidade Surda, sendo, doravante, e por direito, utilizada no ensino dos alunos Surdos (PORTUGAL, 2007, p. 5).
\end{abstract}

Neste sentido, a língua gestual foi introduzida como disciplina de maneira a colocar em prática os princípios legais que regem o sistema educativo. Para que tal acontecesse, foi necessário criar condições para afirmar a cultura surda através do currículo e da transmissão da LGP como língua natural/língua materna.

De salientar que, a aceitação da língua e da cultura surda implicou a presença do professor surdo na escola, o que levou à alteração da constituição da formação pedagógica, da estruturação do ensino e do enquadramento deste profissional. O professor surdo surge como um novo ator (Vaz, 2013) legitimado no discurso das políticas educativas para exercer a prática de ensino da sua língua, contudo constatou-se que este profissional não foi integrado como professor de LGP, mas sim como um formador técnico no ensino, situação que permaneceu inalterada por muito tempo. O presente artigo discute a importância do ensino da língua gestual na educação de surdos como 
http://dx.doi.org/10.5902/1984686X34853

propiciadora do ensino formal da LGP e da presença do professor surdo no ensino regular. De forma a compreender este cenário, recorreu-se à metodologia qualitativa (GONZÁLEZ REY, 2005) interpretativa do conhecimento, que contemplou inicialmente uma análise documental dos Programas Curriculares de Língua Gestual Portuguesa Educação Pré-escolar e Ensino Básico (PORTUGAL, 2007) e Ensino Secundário (PORTUGAL, 2008). Posteriormente, utilizaram-se dados empíricos, preliminares de um estudo de caso numa Escola de Referência em Educação Bilingue de Alunos Surdos (EREBAS) na cidade do Porto, através de entrevistas e observações nas práticas de ensino do docente de LGP no Ensino Básico, em 2018 ${ }^{1}$. Há que destacar a parte introdutória dos procedimentos de análises dos currículos, por trazerem as noções definidoras da sistematização do ensino da LGP na escola regular, estudos teóricos e os históricos. Relativamente aos dados empíricos, enfatizou-se o desenvolvimento do ensino da LGP pela presença do docente surdo e a sua atuação na Educação Básica.

O artigo está organizado em três partes: na primeira aborda a constituição da educação do surdo, pautada num cenário global de recomendações, paradigmas e modelo bilíngue que configuram o campo da educação de surdos em Portugal e as suas alterações mais significativas; seguidamente, discute a aceitação da cultura surda incorporada no currículo da LGP para a contextualização do ensino e, por fim, apresenta a análise dos currículos e dos dados empíricos envolvendo a perceção e práticas de docentes surdos.

\section{A constituição da educação para surdos em Portugal}

A globalização tem alterado o nosso modo de vida por meio da sua intensificação nas relações sociais, políticas, económicas e culturais modelando-as por encaixes e desencaixes (GIDDENS, 1991). O sociólogo francês, Pierre Bourdieu (2007) observou que, apesar de haver uma visão de "independência", as escolhas políticas são dependentes da classe social, da posse de capital e das estruturas relacionais. Neste sentido, Milner (2012, p. 4) enfatiza que "os sistemas políticos se esforçam para responder às demandas do contexto global na estruturação das suas políticas locais". Tais políticas manifestam-se como um sistema humano presente em todos os níveis, do individual ao global, resultado de um mundo moderno. Deste modo, as linhas dos sistemas globais são modeladoras e integradoras nas diretrizes das políticas locais como formas de encaixe ao contexto internacional. Esta relação política representa uma espécie 
http://dx.doi.org/10.5902/1984686X34853

de junção estruturante, distanciando-se da provável maneira, distinta, de como estas políticas locais poderiam comportar-se, caso fossem deixadas sozinhas. Para Bourdieu (2007), o espaço político representa, de maneira diferente, as classes numa estrutura social num campo e com representações dos indivíduos do mundo social.

\footnotetext{
(...) pode-se materializar e sistematizar provisoriamente o conjunto das relações estabelecidas em um esquema do espaço político, visando representar a maneira como as diferentes frações de classes se distribuem umas em relação às outras (...) em relação ao conjunto de "produtos" ou "marcas" de origem política que funcionam como balizas em referências as quais é possível se situar emblemas graças às quais são afirmadas as diferenças (BOURDIEU, 2007, p. 422).
}

O conceito de campo é compreendido, por Bourdieu (2007) como o mundo social constituído por relações de forças e relações simbólicas, onde o "Habitus" explica o agir humano que está preenchido de pensamento. Assim, a estrutura social revela o campo político internacional na determinação de modos das práticas individuais e coletivas que estão presentes no campo educacional, o qual tem sido alterado por diretrizes constituídas no terreno mundial.

Atualmente, a educação de pessoas surdas apresenta um desenho distinto do seu histórico educativo anterior à globalização. De acordo com Svartholm (2014), o campo da educação para surdos começou a ganhar forma, por volta de 1980, quando a educação de surdos na Suécia era similar ao que poderia ser encontrado em outras partes do mundo, em que a educação especial era oferecida às crianças surdas.

Nos dias de hoje, a educação de surdos está caracterizada por orientações e recomendações internacionais, mais visíveis após o reconhecimento da língua gestual e a aceitação do modelo de educação bilíngue. Gomes (2012) sublinha que a atual educação de surdos está inserida na política da educação inclusiva bilíngue, a qual foi se configurando, principalmente, a partir de movimentos políticos e teóricos em contexto global envolvendo o movimento da Escola Inclusiva e a Declaração de Salamanca (UNESCO,1994) influenciando, assim, o campo da Educação Especial.

A educação inclusiva é um conceito novo em diversos países, definindo-se como uma resposta aos desafios educacionais em direitos humanos, mas é também uma reestruturação de culturas, de políticas e de práticas para garantir uma educação de qualidade para todos. Tais necessidades levaram à introdução da língua gestual na escola formal, de forma a garantir o direito dos surdos à educação, a partir da sua língua e da sua cultura. 
http://dx.doi.org/10.5902/1984686X34853

Porém, a constituição deste cenário é marcada pela mudança do paradigma médico para o sócio antropológico, que contribuiu para alterar a concepção da pessoa surda e a visão da surdez. Castilla, Pulido; Cardona (2015, p. 9) acentuam que "Es precisamente dicha concepción sócioantropológica la que da origen a la educación bilingüe ${ }^{2 "}$. Esta "visão sociocultural da surdez" é favorável para o reconhecimento da língua gestual na Europa e, posteriormente no cenário mundial na estruturação da educação inclusiva bilíngue na perspectiva da educação para todos (SKLIAR, 2003, p. 45). A aprendizagem pela língua é entendida como um direito da pessoa surda à educação, tal visão foi sensibilizada pelo modelo bilíngue - bicultural, apoiado por educadores e pesquisadores que defendem a língua gestual para uma aprendizagem natural e como um dos principais meios na comunicação, no ensino e na aprendizagem de pessoas surdas. Em conformidade com Morales e Barrera (2002, p.23), o modelo bilingue envolve duas línguas de modalidades diferentes, de tal maneira que, após o domínio da primeira língua (natural - visual), a língua gestual, os surdos aprendem a segunda língua (sociedadeescrita), a língua portuguesa. Além disso, as pessoas surdas apresentam condições específicas na aprendizagem, revelando-se heterogéneas devendo os sistemas educativos adaptar-se e responder perante as diversidades. Esta conjuntura é importante para sistematizar os ambientes socioculturais, os currículos e as práticas linguísticas e culturais da identidade surda.

Em Portugal, a educação de pessoas surdas segue a tendência mundial da educação inclusiva bilíngue, ao basear-se nas principais soluções e recomendações internacionais sobre as línguas gestuais (COELHO, 1998) pautada nos discursos oficiais do Parlamento Europeu (doc.A2-302/87), na Declaração de Salamanca (UNESCO,1994) e na Resolução 48/96 das Nações Unidas e na Convenção sobre os Direitos das Pessoas com Deficiência (ONU, 2008).

$\mathrm{Na}$ constituição da atual educação para surdos, em Portugal, observou-se a institucionalização, após o reconhecimento da Língua Gestual Portuguesa na Lei Constitucional ํㅜㄴ1997, Art. № 74ํㅡ, ํo 2, alínea h (PORTUGAL, 1997), conforme configuração da imagem 1 abaixo: 
http://dx.doi.org/10.5902/1984686X34853

Figura 1 - A institucionalização da Educação de surdos em Portugal

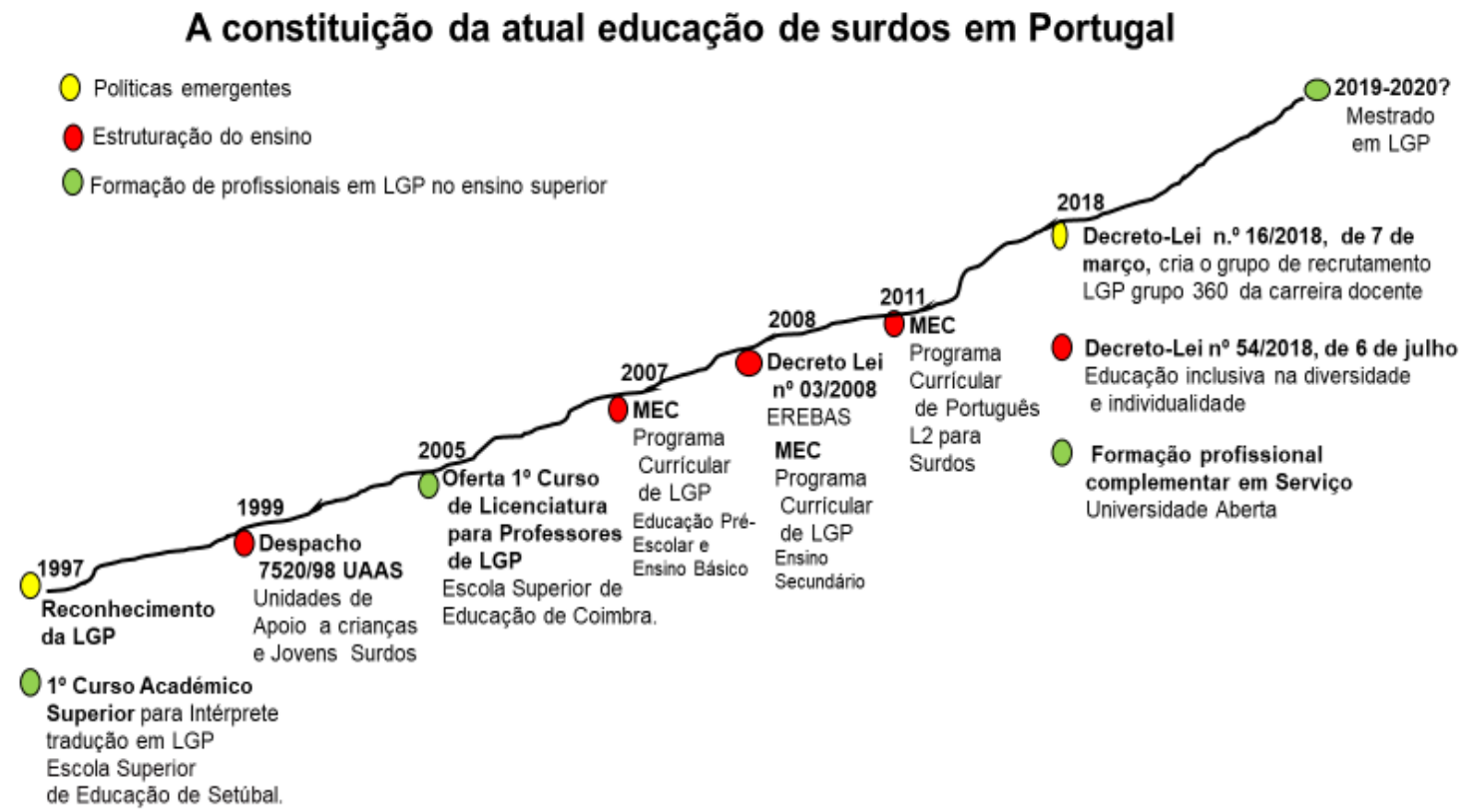

Fonte: Produção dados da investigação, 2019.

Percebe-se, pela análise da imagem 1, que a oficialização do reconhecimento da LGP em 1997, conduziu à estruturação do campo do ensino e da formação de profissionais. A formação de profissionais intérpretes surge primeiro, e só depois é que se estrutura a formação de professores em LGP no ensino superior. Assim, a organização do ensino foi iniciada oficialmente no Despacho o 7520 de 1998 que cria as Unidades de Apoio a Alunos Surdos (UAAS) como princípio de projeto bilingue (PORTUGAL, 1998), e posteriormente, surgiram os Programas Curriculares de LGP na Educação Pré-Escolar e Ensino Básico (PORTUGAL, 2007) e no Ensino Secundário (PORTUGAL, 2008), como primeira L1.

A oficialização da política inclusiva bilingue do Decreto Lei ํํ 03/2008, de 07 de janeiro (PORTUGAL, 2008 b) no Artigo 23. Educação bilingue de alunos surdos organizou as Escolas de Referência para a Educação Bilingue de Alunos Surdos (EREBAS), e estruturou o ensino bilingue, introduzindo a LGP como disciplina. Seguidamente, oficializou-se o Programa Curricular da Língua Portuguesa, como segunda língua L2 para Surdos (PORTUGAL, 2011). Esta constituição do campo da educação de surdos colocou a LGP como disciplina, ao sistematizar a formação de profissionais intérpretes e docentes em LGP e ao organizar o ensino através dos currículos, os quais permitiram o desenvolvimento de práticas pedagógicas com a finalidade de atender as 
http://dx.doi.org/10.5902/1984686X34853

reais necessidades de aprendizagem das crianças surdas. Neste contexto, o docente surdo passou a ter uma representação maior pela sua formação linguística, cultural e pedagógica. Este profissional, entendido como modelo da educação de surdos, lecionava como professor da disciplina de LGP, mas era contratado como técnico. O ano de 2018 marca um período de alterações no campo do trabalho e do ensino, originadas por diversos movimentos dos profissionais e outros segmentos que apoiaram a luta política dos docentes da LGP pela sua integração na carreira como docente da área. A situação de trabalho do docente foi averiguada pelo Grupo de Trabalho da regularização profissional para a docência da LGP regulamentado pelo Despacho nํ 2286/2017, de 16.03 (SEAE, 2017). Após resultados apresentados pelo grupo designado, foram orientadas diretrizes para as novas condições de trabalho docente. A alteração foi oficializada pelo Decreto-Lei n. ${ }^{\circ}$ 16/2018, de 7 de março, que criou o grupo 360 de recrutamento da Língua Gestual Portuguesa, corrigindo a situação dos formadores de LGP para a sua integração na carreira como docente por concurso.

Este decreto prevê a alteração na habilitação profissional e certificação para a docência no domínio da LGP, por meio do grau de mestre ainda em processo de definição. Entretanto, os docentes em exercício de funções estão, atualmente, a participar num curso de formação em LGP, promovido pela Universidade Aberta, para confirmar a sua formação pedagógica nesta fase de transição, de formador técnico para professor.

Novas alterações no Decreto-Lei nº 03/2008 foram expressas no Decreto-Lei no 54/2018, de 6 de julho, da educação inclusiva que estabelece princípios e normas para garantir uma inclusão que visa responder à diversidade das necessidades e potencialidades de todos e de cada um dos alunos.

As alterações na política local demonstram o ajuste no próprio sistema de ensino perante a situação verificada anteriormente. De todas as alterações, a criação do grupo 360 , foi a mais significativa para os professores, visto que estes anteriormente foram integrados apenas como técnicos no espaço educativo originando, assim, um contexto profissional de desencaixe e tensões, o que conduziu à constituição de pressões dos docentes para saírem do estado da semidocência. Nesta situação constatou-se que a adoção do sistema bilíngue na educação de surdos, em Portugal, implicou na aceitação da cultura surda na escola, mas não resultou, inicialmente, na aceitação do professor surdo como um profissional da docência. 


\section{A aceitação da cultura surda e a LGP na escola}

A introdução da língua gestual na escola necessitou, por parte dos sistemas educacionais, de uma compreensão maior da cultura da comunidade surda. O seu desenvolvimento enquanto disciplina demandou uma nova organização na rotina da escola através da materialização do currículo e de um ensino que revelasse a essência das práticas culturais do povo surdo. Assim, a língua gestual é desenvolvida por uma contextualização curricular (FERNANDES; FIGUEIREDO, 2011) envolvendo a língua e a cultura surda de modo a favorecer a sistematização de ensino atrelado às marcas culturais do povo surdo.

Há um consenso na literatura sobre a influência dos estudos culturais (LOPES, 2013) na organização de políticas educativas para grupos minoritários, inclusive na educação de surdos, ao fundamentar o ensino da língua gestual na perspetiva da cultura surda na estruturação do seu currículo. Ao entender a cultura como culturas alternativas, significa perceber as outras identidades além das existentes no enquadramento maior. Dessa forma, a cultura é pensada e associada às práticas e os seus praticantes em determinados espaços.

A cultura é, para Geertz (1989) uma ideia profundamente comprometida que não podemos igorar de fazer e, por isso, esta declaração dá visibilidade à noção de que a cultura está incorporada no pensar e no agir do praticante. Adota-se, deste modo, a visão da cultura como resultado da prática social.

$\mathrm{Na}$ educação de surdos há uma visão da cultura como direito, o que tem alterado a noção e as práticas de ensino para que as crianças surdas tenham a língua materna como ponto de partida.

A língua gestual é entendida como diferente da oral, por se caracterizar, principalmente, como uma língua visual-motora, própria do sujeito surdo e apreendida de maneira espontânea. Perante isto, há que salientar que o currículo precisa ser diferente ao do ouvinte de forma a corresponder às reais necessidades de aprendizagem das crianças surdas. As mudanças nas conceções orientam uma educação de surdos como o lugar do sujeito surdo construir a sua subjetividade, onde a identidade cultural é formada através do seu pertencimento a sua cultura. Então, a ligação cultura e educação vem a contribuir nos estudos surdos e nas práticas de ensino conectando-as à visão da cultura e a identidade do sujeito surdo como sujeito sócioantropológico. 
http://dx.doi.org/10.5902/1984686X34853

No currículo podemos captar a indicação para um ensino em que a cultura surda não deve seguir a visão da cultura única ouvinte, mas uma cultura plural e como representação da diferença (HALL, 2003; LADD, 2013; SKLIAR,2003; PERLIN, 2013). À vista disso, a cultura surda, ao ser entendida como diferente, é incorporada na escola para orientar as mudanças no ensino e na aprendizagem de crianças surdas alterando o contexto escolar na organização de espaços bilíngues, dos currículos e das práticas educativas.

Esta mudança registrada nos últimos anos não é, nem deve ser compreendida como uma mudança metodológica dentro do mesmo paradigma da escolarização. O que está mudando são as concepções sobre o sujeito surdo, as descrições em torno da sua língua, as definições sobre as políticas educacionais, a análise das relações de saberes e poderes entre adultos surdos e adultos ouvintes, etc.(SKLIAR, 1998, p.7)

Por conseguinte, a "internacionalização do currículo em particular" (THIESEN, 2017, p. 995) na educação de surdos e as mudanças no paradigma da escolarização devem refletir alterações na forma de ensinar e aprender a língua gestual na organização do currículo. Então, este ensino deve aproximar-se do contexto desta língua na comunidade surda, no qual a aprendizagem ocorre de maneira espontânea. Skliar e Lunari (1999) argumentam que há muito tempo o currículo deixou de ser visto como elemento neutro e inocente de transmissão desinteressada, este é um dispositivo cultural e social, um território político modelado por acordos e interesses

La nueva propuesta, difundida actualmente en buena parte del mundo y designada con el término genérico de educación bilingüe, se orienta al cumplimiento de cuatro objetivos generalmente olvidados o deshechados en la escuela especial: la creación de un ambiente lingüístico apropiado a las formas particulares de procesamiento cognitivo y comunicativo de los niños sordos; el desarrollo socio-emocional íntegro de los niños sordos, a partir de su identificación con adultos sordos; la posibilidad de que estos niños desarrollen una teoría sobre el mundo sin condicionamientos de ninguna naturaleza y; el acceso completo a la información curricular y cultural (SKLAIR; LUNARI, 1999,p. 1).

Devido à aceitação e sistematização do modelo bilingue (KOZLOWSKI, 1995, p.3), o currículo da língua gestual foi organizado para enfatizar traços significativos da cultura surda na sua implementação na escola. De acordo com Gómez (2012, p. 2) o "enfoque bilingüe/bicultural mostra a compreensão de uma aprendizagem diferente para crianças surdas, em relação aos ouvintes". Consequentemente, esta abordagem bilingue introduziu o aspeto cultural de surdos como um ponto que os diferencia (DORZIAT, 2011, p. 32) e é visível em currículos de ensino da sua língua. Esta perspectiva tem sido assumida, seja 
http://dx.doi.org/10.5902/1984686X34853

de forma direta ou indireta, nos programas curriculares como uma das orientações que têm alterado a educação de surdos através do programa curricular e, para Skliar e Lunardi (1999, p.1), esta repercussão é a nível global para o ensino da língua gestual.

Este sistema bilíngue está explícito nos programas curriculares de Língua Gestual Portuguesa para a Educação Pré-Escolar e Ensino Básico (PORTUGAL, 2007) e Ensino Secundário (PORTUGAL, 2008), em Portugal. Os programas ressaltam que a educação bilíngue deve ser encarada como um direito, onde as línguas gestuais são patrimônios da humanidade e que expressam a cultura da comunidade surda. Além disso, descrevem que o currículo emerge intensificado pelo contexto global, após a demanda do reconhecimento da língua gestual dignificada enquanto primeira língua da comunidade surda, legitimando assim, um currículo com aceitação da cultura surda na escola como direito. Os currículos evidenciam que esta cultura possui vários dispositivos carregados de múltiplos significados e elementos que podem definir a identidade, entre eles a linguagem.

Neste caso, o ensino da LGP deve possibilitar o direito da cultura surda de ser entendida como diferente da cultura que sempre existiu no contexto da educação formal. À vista disso, o currículo apresenta nos pressupostos essenciais argumentos de que a criança surda depende da aquisição e do desenvolvimento da sua língua, para que o seu pensamento se estruture (PORTUGAL, 2007). Afirma também que a língua natural para os surdos é a língua gestual, logo a sua aquisição plena constitui um direito e o seu domínio é decisivo no desenvolvimento individual. Por consequência, a disciplina da LGP destina-se a todas as crianças surdas, independentemente do tipo e grau de surdez, devendo-se adaptá-la para todas, pela heterogeneidade presente no contexto escolar. Sendo, portanto, necessário constituir um espaço próprio para o processo de ensino e aprendizagem para promoção dos vários aspetos formativos, entre estes, o linguístico e o cultural, utilizados por pessoas surdas portuguesas.

A LGP é uma língua visuo-motora, cuja produção se processa através dos gestos e das expressões facial e corporal, e cuja percepção se realiza através da visão. Esta língua é utilizada por pessoas Surdas portuguesas na sua comunicação, sendo uma marca importante da sua identidade. É o elemento mais unificador na Comunidade Surda, enquanto meio de transmissão de valores e da herança cultural das pessoas surdas (PORTUGAL, 2007, p. 8).

Salienta-se a língua gestual como a marca da identidade e da cultura, onde a escola sistematiza novas formas de unir os surdos. 
http://dx.doi.org/10.5902/1984686X34853

Por fim, compreendeu-se que a cultura surda foi incorporada no currículo da LGP para contextualizar a organização do ensino, no intuito de responder a uma demanda do contexto mundial, mas também, por haver uma reivindicação local. O enfoque bilíngue fundamentou o currículo da língua gestual, a constituição do ambiente linguístico e a promoção de práticas diferenciadas pela presença do adulto surdo objetivando propiciar outra educação para crianças surdas. O currículo orienta para a potencialização das características dos sujeitos surdos pela LGP como a principal marca cultural e linguística. É notável que o apoio internacional modernizou e modelou políticas para a educação para surdos por diretrizes. Os sistemas educacionais locais ao aderirem às orientações estabeleceram estruturas de organização da língua gestual, principalmente, nos programas curriculares que incorporam a cultura surda e legitimaram a LGP através dos aspetos linguísticos, culturais e pedagógicas na escola.

\section{O currículo de LGP e a presença do docente surdo}

Olhando o Programa Curricular de LGP para a Educação Pré-Escolar e Ensino Básico (PORTUGAL, 2007) e o Programa Curricular de LGP para o ensino secundário (PORTUGAL, 2008) percebe-se nas suas orientações para as práticas de ensino, que o elo de ligação desta disciplina com a cultura surda é o seu principal praticante cultural, o adulto surdo. O docente surdo é idealizado como o sujeito contextualizado a nível linguístico e cultural nos currículos.

Estes programas enfatizam a importância da presença do adulto surdo nos seus pressupostos essenciais, nos requisitos para as competências no desenvolvimento do ensino de LGP e na educação bilíngue: LGP e LP, havendo apenas adequações ao nível do ensino proposto. De um modo geral, os currículos descrevem a LGP como uma língua da comunidade surda, a qual possui uma cultura visual, onde o educador surdo é o principal legitimador deste ensino.

O programa curricular da disciplina de Língua Gestual Portuguesa (LGP) para o ensino secundário surge no seguimento das aprendizagens desenvolvidas nesta disciplina desde a primeira infância até ao final do ensino básico. Depreende-se que o aluno Surdo adquiriu naturalmente a LGP e aprofundou competências na sua primeira língua durante todo o percurso escolar, numa lógica de igualdade de oportunidades no acesso à educação, defendida pelos princípios legais expostos anteriormente (vide Introdução do "Programa Curricular de Língua Gestual Portuguesa Educação Pré-Escolar e Ensino Básico"). Reforça-se aqui a necessidade desta língua ser reconhecida e dignificada pelo seu real estatuto, enquanto primeira língua da Comunidade Surda, e de, por direito, ser garantida a sua utilização no ensino dos alunos Surdos. Para uma verdadeira educação 
http://dx.doi.org/10.5902/1984686X34853

bilíngue, há que preservar a LGP, enquanto expressão cultural da Comunidade Surda, respeitando o papel fundamental do docente Surdo, enquanto transmissor legítimo da língua e da cultura da Comunidade e enquanto modelo de identificação natural para as crianças e jovens Surdos. (PORTUGAL, 2008 a, p.4).

Neste sentido, as orientações curriculares para o ensino de LGP estão baseadas na perspectiva bilíngue da língua materna, como primeira língua, atribuindo assim, um julgamento cultural ao profissional no desenvolvimento das suas práticas de ensino da LGP:

O docente de LGP terá de necessariamente dominar a LGP enquanto primeira língua materna, de forma a poder ensiná-la corretamente como tal. O Docente de LGP deve ser capaz de adequar o Currículo às necessidades, capacidades, atividades e experiências dos seus alunos, desenvolvendo objetivos, atividades de programação, planificação, estratégias pedagógicas, materiais e recursos didáticos (PORTUGAL, 2007, p. 7).

Esta visão do ensino pelo docente possuidor da LGP, enquanto primeira língua/língua materna é idealizada e afirmada na e para a profissão. Os programas curriculares destacam também que "Esta disciplina terá de ser necessariamente lecionada por modelos linguístico-culturais, adultos Surdos falantes nativos de LGP e possuidores de uma identidade intrínseca à pessoa Surda."(PORTUGAL, 2007, p. 25). Tais requisitos descritos sobressaem na seleção dos profissionais, em que se realça a prioridade ao docente surdo, apesar de haver na formação para docentes de LGP, pessoas surdas e ouvintes. Esta situação pode ser alterada diante da expansão da disciplina e da definição do perfil profissional na nova carreira docente no ensino da LGP.

A consolidação da presença do docente surdo na escola e no ensino da LGP é justificada como essencial nesta prática de ensino pelo seu pertencimento à cultura de grupos surdos, mas também por sua importância no desenvolvimento e na constituição da identidade da criança surda. Segundo Correia (2017, p.49), "a criança quer tenha pais surdos ou ouvintes é obrigada a estar em dois mundos, logo a criança é bilíngue, na medida, em que atua nos dois mundos." Daí a relevância da presença do docente surdo na escola como potencializadora nas relações de aprendizagem, no uso da língua e na identificação da criança com a cultura.

Já em relação à questão da primeira língua, Svartholm (2014, p. 35) define os termos primeira língua e segunda língua. O termo "primeira língua" é usado não só para indicar a ordem em que a língua é aprendida, mas também pelo seu papel no 
http://dx.doi.org/10.5902/1984686X34853

desenvolvimento (cognitivo, emocional, social) da criança. Já o termo "segunda língua" define-a como a língua de uso da sociedade. Lopes e Veiga-Neto (2006) descrevem que a primeira língua é definida pelos surdos como a sua língua materna, sendo reivindicada como direito de uso permanente e marca cultural das pessoas surdas.

A orientação é para o ensino da LGP pelo possuidor da língua como primeira língua, onde este é identificado como fio da cultura e da identidade surda, o que acentua a impressão da língua como principal elemento determinante da cultura. Embora haja uma compreensão da importância da linguagem como um dos aspetos que constituem a cultura, Barth (1998, p. 32) observa que é um erro considerá-la como fator determinante da identidade étnica, pois, devemos verificar fatores e traços culturais, onde o grupo étnico é o sujeito da etnicidade e conteúdo da cultura. Temos que revelar o sujeito da cultura para considerá-lo como o ator social, que pode ser o "eu ou o nós da etnicidade". Desta forma, a identidade não é fixa, mas carrega um conteúdo representativo do grupo e também deste sujeito cultural. O estudo de Silva (2002) acentua que a questão e configuração discursiva da surdez é afirmada e performatizada como particularidade étnico-linguística, o que justifica os discursos de ligação da língua com a identidade confirmada nos currículos como essencial.

Em relação ao desenvolvimento de competências em LGP, os programas curriculares descrevem também que o docente terá de, necessariamente, ter formação profissional na área da LGP e dominá-la como primeira língua para lecionar a disciplina. Ao colocar a língua no âmbito da educação formal tornou-se necessário estruturar processos na formação de docentes no ensino superior diferenciando-se da formação anterior nas comunidades surdas. Consequentemente a atuação para o ensino da língua no espaço escolar requer a formação de professores com competências pedagógicas cada vez mais formais, portanto, agora mais acadêmica. Diante disto, foi necessário a criação de estruturas para formação e o ensino potencializadores das condições pedagógicas que permitiram o desenvolvimento da LGP (L1) e da Língua Portuguesa (L2). Ao abordar a educação bilíngue: LGP e LP, o currículo de LGP é definido como um instrumento regulador na aquisição e desenvolvimento da língua, na organização das práticas de ensino e na formação do docente. A sua sistematização é constituída por meio das áreas nucleares instituídas como competências através das componentes de: Interação em LGP, Literacia em LGP, Estudo da língua, LGP, comunidade e cultura. 
http://dx.doi.org/10.5902/1984686X34853

No intuito do aluno surdo adquirir e desenvolver a sua língua é de suma importância uma prática de ensino de LGP realizada num contexto real. Para tal, o docente deve fundamentar-se numa ação orientada (FREIRE, 1997) por diretrizes constituídas por valores, crenças e teorias individuais e coletivas conectadas à sua forma de atuar como educador e sujeito cultural. É então, vital utilizar situações e contextos reais, na prática, de ensino em diversos setores e atividades criando, assim, um ambiente propício para a aquisição e desenvolvimento da LGP.

Ressalta-se também que o docente de LGP deve ser capaz de adequar o currículo às necessidades, às capacidades, ao conhecimento e às experiências dos seus alunos, desenvolvendo objetivos, atividades de programação, planificação, estratégias pedagógicas, materiais e recursos didáticos (PORTUGAL, 2007).

Esta ideia de ensino conectado em situações reais, rotineiras e voltadas ao contexto prático da vida diária é teoricamente compreendido no conceito de cultura como a prática do praticante (GEERTZ, 1989) distinguindo-o do conceito da alta cultura. O estudo de Afonso (2004) sobre o currículo, aponta que a presença dos formadores (docentes) surdos têm maior visibilidade ao ensino da Língua Gestual, e que eles são uma presença fundamental na educação de surdos apesar de apresentarem dificuldades relativas na formação de professores.

A aceitação da cultura surda no contexto escolar encaixou o sujeito da língua materna integrando-o como um marcador cultural e profissional na disciplina da LGP e na educação de surdos. Esta condição foi possibilitada por uma estruturação de práticas pedagógicas num ambiente linguístico organizado pela política inclusiva bilíngue, ao implementar as EREBAS enquanto escolas de referência como um espaço de concentração de alunos surdos, apesar de haver outras escolas com alunos e docentes surdos. As práticas de ensino da LGP realizadas nas EREBAS expressam a noção de ações bilíngues numa pequena cultura (HOLLIDAY, 1999) no ambiente escolar, onde a língua e a cultura são encaixados. A introdução da língua na escola constituiu-se, assim, uma resposta também às pessoas surdas, mas sua educação segue um modelo recortado de um projeto maior da pedagogização da língua gestual na escola.

A escola é um espaço onde o ensino se exerce de forma intencional a partir de um conjunto de princípios selecionados que guiarão professores e alunos, bem como todos aqueles que direta e ou indiretamente se relacionam com ela. Com a tarefa de educar, a escola é uma das grandes máquinas que trabalham na produção de sujeitos dóceis, adaptados a um tipo de sociedade (LOPES; VEIGA-NETO, 2006, p. 92). 
http://dx.doi.org/10.5902/1984686X34853

Para estes autores, a escola e o professor passam a delegar e assumir uma pedagogização que reflete os valores e as práticas da comunidade surda, mas é estruturada de acordo com o que é proposto e indicado pelo sistema educativo, onde "A escola, enquanto espaço social é organizada por uma cultura própria" (BOURDIEU, 2007, p. 101). A escola formal passou por transformações ao adotar o sistema inclusivo bilíngue, sobretudo no que concerne ao reconhecimento dos bens culturais e práticas específicas da comunidade surda. As transformações na escola pelo sistema inclusivo bilíngue têm proposto outra lógica para resolver situações específicas de aprendizagem dos alunos. Este processo conduziu à aceitação da cultura e do docente surdo na formação de profissionais e nas escolas com alunos surdos.

Quadro 1 - A presença de docentes surdos no ensino de LGP

\begin{tabular}{|l|l|}
\hline $\begin{array}{l}\text { Ensino na formação de profissionais em } \\
\text { LGP }\end{array}$ & Ensino de LGP nas escolas \\
\hline Curso de Licenciatura na Docência em LGP & $\begin{array}{l}\text { Pré-Escola e na Educação Básica: } 1^{\circ} \text { ciclo, } 2^{\circ} \text { ciclo e } \\
3^{\circ} \text { ciclo }\end{array}$ \\
\hline Curso de Interpretação Tradução em LGP & Ensino Secundário: $10^{\circ}$ ano, $11^{\circ}$ ano e $12^{\circ}$ ano \\
\hline
\end{tabular}

Fonte: Produção de dados da investigação, 2019.

Os dados apresentados no quadro 1 revelam a presença dos docentes surdos nas modalidades do ensino básico ao superior. Esta aceitação do docente surdo na escola é fruto de uma longa trajetória de lutas pelo reconhecimento da língua, do ensino bilingue e do profissional. Na formação de profissionais em LGP, o docente atua preferencialmente nas disciplinas de LGP, onde a maioria dos alunos são ouvintes. Já no ensino em escolas, os docentes atuam, principalmente, em turmas de alunos surdos. De acordo, com os dados empíricos observados numa EREBAS verificou-se que no primeiro ciclo os docentes surdos com alunos surdos, atuam de duas formas: primeiramente, como docente de apoio nas aulas dos professores ouvintes responsáveis pelas turmas, e posteriormente, como docente principal da turma, com dois momentos de aula de LGP durante a semana. Já no segundo e terceiro ciclo, o docente surdo tem autonomia ao atuar, principalmente, no ensino de LGP possuindo dois, três, quatro ou mais horários de aulas durante a semana e em todo ano letivo.

Nas suas aulas, os docentes surdos, baseiam o ensino da língua no currículo de LGP nos seus diferentes níveis, procurando atender à realidade, mas adaptando-o. Um 
currículo flexível é constituído nas suas atividades, de modo a atender as situações das aulas, tratando-se, portanto, de um currículo mais abrangente ao fundamentar o trabalho dos professores às necessidades dos estudantes nas suas aprendizagens.

Os dados empíricos levantados por meio das entrevistas revelaram a importância do currículo, na prática, de ensino dos docentes conforme quadro 2 abaixo:

Quadro 2 - Extratos de entrevistas com professores surdos

\begin{tabular}{l}
\hline PS.03: Temos que seguir o programa curricular da Língua Gestual Portuguesa, da LGP, \\
por exemplo, falar da história dos surdos, fazer a interpretação da História, tentar perceber que \\
conceitos é que eles conhecem e adaptar os nossos gestos aos conceitos para que eles se \\
desenvolvam cognitivamente, para que percebam a lógica da vida em sociedade, mas ao \\
mesmo tempo ensinando-Ihes os gestos. \\
\hline PS.05: (...) seguimos um programa curricular, aprovado pelo Governo em 2008, tivemos \\
formação específica do Governo para isso e então nós seguimos este programa curricular nas \\
nossas aulas.(...) \\
\hline PS.06: (...). Eu posso ir trabalhar para um outro ciclo, agora estou na pré, mas posso não ficar \\
para sempre aqui, posso ir para o 1.․o ciclo, posso ir para o 2..., 3.o, para o secundário, não é? \\
Eu tenho que saber, conhecer bem o programa curricular, ter planos que me permitam \\
depois ensinar a língua gestual.(..) \\
\hline PS.07: Eu acho que a cultura surda é importante. Normalmente as crianças surdas têm pais \\
ouvintes, então há muitas dificuldades. As crianças sentem-se diferentes, eu sei o que elas \\
sentem, isso aconteceu comigo. Como é que eu vou comunicar com os meus pais? E eu, \\
muitas vezes, dou o meu exemplo, eu digo-lhes "Se não conseguires chamar alguém, bates na \\
mesa. Queres entrar num espaço, queres bater à porta, mas não sabes se te deixarão entrar? \\
(...) \\
\hline PS.09: Claro que eu sigo o programa de LG, e uma das áreas que o programa tem é "LGP, \\
comunidade e cultura". E a maioria, fala um bocadinho sobre o movimento associativo, um \\
bocadinho sobre o conhecer pessoas surdas, pessoas diferentes de áreas diferentes, de \\
gerações diferentes, ou seja, o objetivo é permitir que os alunos tenham contacto com outras \\
pessoas surdas, para que não sejam só as da escola. (...)
\end{tabular}

Fonte: Produção de dados da investigação, 2019.

Estes excertos das entrevistas com docentes de LGP numa EREBAS explicitam a importância do currículo no ensino, mas ressaltam também o papel relevante da cultura na aprendizagem das crianças surdas. Observou-se que dos cinco entrevistados, quatro destacaram o currículo, e três salientaram a importância da cultura surda na sua prática de ensino.

Nas observações das aulas, foi verificado que os professores preparam temáticas e produções de materiais em LGP, de modo cuidadoso para assegurar a relação com 0 conteúdo e as atividades atreladas às práticas e conhecimentos significativos da cultura surda.

O uso do tempo, a relação com o currículo e as produções são alvo de constantes ajustes pelos professores, para que as crianças compreendam e aprendam os gestos e os seus significados em todos os estudos temáticos propostos. 
http://dx.doi.org/10.5902/1984686X34853

Neste sentido, a flexibilidade é marcante na relação de como trabalhar para que as crianças não só aprendam os gestos, mas compreendam o seu significado na utilização no quotidiano diário. O ensino para as crianças é atualizado ao contexto social estudado, visto que muitos são filhos de pais ouvintes com acesso reduzido ao diálogo dentro da sua casa e no contexto social maior. Neste cenário da prática no ensino de LGP, o português escrito é utilizado na interação pedagógica pelo uso de vocabulários e situações que apresentam o contexto social disponível na internet, em livros, nas produções próprias do professor, em documentos e em vídeos. Além disso, o professor resgata dados da história, dos valores e das práticas da cultura surda, havendo assim, uma aglutinação na compreensão entre o escrito da sociedade e o gestual da comunidade surda.

\section{Considerações finais}

A pedagogização da educação de surdos proposta por diretrizes internacionais foi incorporada nas políticas locais e adaptada ao contexto de ensino. Em Portugal, o ensino da língua gestual como disciplina implicou na aceitação da cultura surda na escola contextualizada no currículo e nas práticas pedagógicas. Ao discutir a importância da pedagogização da língua gestual na educação de surdos constatou-se que a introdução da LGP no ensino formal demandou a presença do professor surdo na escola regular. Esta contextualização no ensino da língua materna para a educação das crianças surdas, justifica-se como favorável ao seu desenvolvimento integral. Neste cenário, o docente surdo é posto como essencial na transmissão do ensino ao assegurar às crianças o contato com o adulto surdo, igualmente como o modelo desta cultura na escola.

Verificou-se nos currículos da LGP que a cultura surda é entendida como uma representação da diferença, incorporada para orientar as mudanças no ensino e na aprendizagem no contexto escolar. O que pode significar que esta aceitação modernizou e modelou a educação de surdos por meio da língua. Observou-se também nos documentos oficiais a afirmação da perspectiva socioantropológica, linguística e cultural no ensino bilíngue de alunos surdos, em que a língua gestual é o ponto de partida para garantir o cumprimento da política global.

A presença do docente surdo na escola regular constitui um novo percurso na história da educação, no ensino da língua ao integrar um novo ator na profissão no contexto educacional. $\mathrm{O}$ docente surdo tem um papel importante na estruturação e prática 
http://dx.doi.org/10.5902/1984686X34853

no ensino de LGP, apesar da história da sua profissão evidenciar, inicialmente, uma desvalorização no trabalho educacional.

Por fim, ao analisar-se a constituição do campo da educação de surdos em Portugal, verificou-se que a adoção do sistema bilíngue implicou na aceitação da língua e da cultura surda, asseguradas no currículo da LGP e pela presença do docente surdo na escola, mas não garantiu inicialmente o enquadramento de docentes surdos como professores. Portanto, as atuais alterações previstas no âmbito da profissão e do ensino devem prever novas mudanças na atuação profissional, no currículo e no ensino da LGP podendo, assim, possibilitar a inovação das práticas pedagógicas.

\section{Referências}

AFONSO, Carlos Manuel Magalhães. Dos discursos e possibilidades de construção de um currículo contra - hegemónico na educação de surdos. Tese de doutoramento da Universidade do Porto. Porto, Portugal: UP, 2004.

BARTH, Frederick. Grupos Étnicos e suas fronteiras. In: POUTIGNAT, P. J. S. F. Teorias da etnicidade. Seguido de grupos étnicos e suas fronteiras de Fredrik Barth. São Paulo: UNESP, 1998.

BOURDIEU, Pierre. A Distinção: crítica social do julgamento. São Paulo: Edusp; Porto Alegre, RS: Zouk, 2007.

CASTILLA, Carmen Aura Arias; PULIDO, Diana Jennifer Acosta; CARDONA, Jaime Alberto Ayala. Antecedentes en atención pedagógica a la población sorda: una revisión contextual. Revista Iberoamericana de Psicología: Ciencia Y Tecnología, 8 (1), p. 7-15, jun. 2015.

COELHO, Orquídea. (E) depois da escola (?): formação, autoformação e a transição para a vida activa dos surdos em Portugal. Dissertação de Mestrado Animação e gestão da formação. Porto, Portugal: Universidade do Porto, 1998.

CORREIA, Maria de Fátima Costa de Sá. E do gesto se faz mundo aprender/ensinar filosofia em LGP. Tese de doutoramento. Porto, Portugal: Universidade do Porto, 2017.

DORZIAT, Ana. Estudos Surdos diferentes olhares. Porto Alegre: Editora Mediação, 2011.

FERNANDES, Preciosa; FIGUEIREDO, Carla. Contextualização curricular: subsídios para novas significações. Interacções, n. 22, p.136-177, 2012. Disponível em: https://revistas.rcaap.pt/interaccoes. Acesso em: 10 jan.2018.

FREIRE, Paulo. Educação como prática da liberdade. Rio de Janeiro, Brasil: Paz e Terra, 1997. 
http://dx.doi.org/10.5902/1984686X34853

GEERTZ, Clifford. A interpretação das culturas. Rio de Janeiro, Brasil: LTC, 1989.

GIDDENS, Anthony. As consequências da modernidade. São Paulo: Editora Unesp, 1991.

GOMES, Maria do Céu Ferreira. A Reconfiguração Política da Surdez e da Educação de Surdos em Portugal: Entre os Discursos Identitários e os Discursos de Regulação. Tese de doutoramento. Porto, Portugal: Universidade do Porto, 2012.

GÓMEZ, Robles M. Tendencia educativa bilingüe y bicultural para la educación del sordo. Un nuevo camino hacia la inclusión. Unirevista.es, n.1- 10, mayo, 2012. Disponível em: http://rabida.uhu.es/dspace/handle/10272/6148. Acesso em: mar. 2018.

GONZÁLEZ REY, Fernando. Pesquisa qualitativa e subjetividade: os processos de construção da informação. São Paulo: Pioneira Thomson Learning, 2005.

HALL, Stuart. Da Diáspora: identidades e Mediações culturais. Belo Horizonte: Editora UFMG; Brasília: Representação da Unesco no Brasil, 2003.

HOLLIDAY, Adrian. Small Cultures. Applied linguistic. Oxford University, 1999. Disponivel em: http://www.scirp.org/reference/ReferencesPapers.aspx?Referencel $D=836688$. Acesso em: 02 fev. 2018.

KOZLOWSKI, Lorena. O modelo bilíngue bicultural na educação de surdos. Distúrbio da comunicação, São Paulo, 1995. Disponível em: https://revistas.pucsp.br/index.php/dic /arti cle/view/11074. Acesso em: 20 jan. 2018.

LADD, Paddy. A Final Frontier - Can Deafhood Pedagogies Revolutionize Deaf Education? CSD, Fermont, 2013. Disponível em: http://deafhoodfoundation.org/vlog/ wpcontent/uploads/2013/10/Fremont-Deaf-Pedagogies-2013COPYRIGHTED.pdf. Acesso em: 04 mar. 2017.

LOPES, Maura Corcini; VEIGA-NETO, Alfredo. Marcadores culturais surdos: quando eles se constituem no espaço escolar. Perspectiva, Florianópolis. v. 24. n. Especial, jul./dez. 81-100, 2006. Disponível em: https://periodicos.ufsc.br/index.php/perspec tiva/article/view/10541. Acesso em: 11 jan. 2018.

LOPES, Alice Casimiro. Teorias Pós-Críticas, política e Currículo. Educação, Sociedade \& Culturas, no 39, 7-23, 2013. Disponivel em: https://www.fpce.up.pt /ciie /sites/default /files/ ESC39_A_C_Lopes_abstracts.pdf. Acesso em: 17 fev.2018.

MILNER, Helen V. "Globalization." BADIE, B.; BERG-SCHLOSSER, D.; MORLINO, L. International Encyclopedia of Political Science. Thousand Oaks, CA: SAGE, 2011. 973984, 2012. Disponível em: http://dx.doi.org/10.4135/97814129941 63. Acesso em: 11 jul. 2018.

MORALES, Ana María; BARRERA, Lucía Fraca de. Hacia una política educativa para la enseñanza y el Aprendizaje de la lengua escrita En sordos. Investigación y Postgrado, Vol. 17, N², 2002. Disponível em: http://ve.scielo.org/scielo.php?Script=sci_arttext\&pid= S131600872002000200004. Acesso em: 13 mar. 2018. 
ONU. Convenção sobre os direitos das pessoas com deficiência. 2008. Disponível em: https://www.fundacaodorina.org.br/a-fundacao/deficiencia-visual/convencao-da-onu-sobredireitos-das-pessoas-com-deficiencia/. Acesso em: 10 jul.2018.

PORTUGAL. Constituição da República Portuguesa de 1997. Reconhece a LGP como língua da comunidade surda Portuguesa, 1997. Diário da República n. 218/1997, Série I-A de 1997-09-20. Lei Constitucional.

PORTUGAL. Despacho n. ${ }^{\circ}$ 7520/98 (2. 로érie). Diário da República n. 104/1998, Série II de 1998-05-06, 1998. Ministério da Educação - Secretário de Estado da Educação e Inovação, 2018.

PORTUGAL. Direção-Geral de Inovação e de Desenvolvimento Curricular. Programa curricular de língua gestual portuguesa educação pré-escolar e ensino básico. Ministério da educação, direcção-geral de inovação e de desenvolvimento curricular, 2007.

PORTUGAL. Direção-Geral de Inovação e de Desenvolvimento Curricular. Programa curricular de língua gestual portuguesa ensino Secundário. Ministério da educação, direcção-geral de inovação e de desenvolvimento curricular, 2008 a.

PORTUGAL. Decreto-Lei n.ำ 3/2008, de 7 de Janeiro. Apoios especializados a prestar na educação pré-escolar e nos ensinos básico e secundário dos sectores público, particular e cooperativo. Diário da República n. 4/2008, Série I de 2008-01-07. Ministério da educação, $2008 \mathrm{~b}$.

PORTUGAL. Decreto-Lei n. $\stackrel{0}{16 / 2018}$ de 7 de março. O presente decreto - lei cria o grupo de recrutamento da língua gestual portuguesa (LGP), Diário da República n. 0 47/2018, Série I de 2018-03-07, 2018.

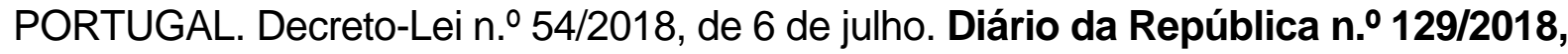
Série I de 2018-07-06, Ministério da Educação, 2018.

SEAE. Despacho n.ำ 2286/2017, de 16 de março. Relatório Final produzido pelo Grupo de Trabalho de análise para enquadramento do docente da LPG, Diário da República $\mathbf{n}$.ㅇ

54/2017, Série II de 2017-03-16, Educação - Gabinete da Secretária de Estado Adjunta e da Educação, 2017.

SILVA, César Augusto de Assis. Cultura Surda: Agentes religiosos e a construção de uma identidade. São Paulo: Terceiro Nome, 2002.

SVARTHOLM, Kristina. 35 anos de Educação Bilíngue de surdos - e então? Educar em Revista, Curitiba, Brasil, Edição Especial n. 2. Editora UFPR, p. 33-50, 2014.

SKLIAR, Carlos; LUNARDI, Márcia Lise. Estudios Sordos y Estudios Culturales en Educación: un debate entre maestros oyentes y sordos sobre el curriculum escolar. Revista Bilinguismos em Educação de Surdos. Bogotá Colômbia,1999. Disponível em:https://cultura-sorda.org/wp-content/uploads/2015/03/Skliar-Lunardi_Estudios-sor dos_1999.pdf. Acesso em: 6 jul.2018. 
http://dx.doi.org/10.5902/1984686X34853

SKLIAR, Carlos; MASSONE, María Ignacia.; VEINBERG, Silvana. El acceso de los niños sordos al bilingüismo y al biculturalismo, 1995. Disponível em:

http://www.cultura-sorda.eu. Acesso em: 2 jun.2018.

SKLIAR, Carlos. Pedagogia (improvável) da diferença: e se o outro não estivesse ai? Rio de Janeiro, Brasil: DP\&A., 2003.

SKLIAR. Carlos. A surdez: um olhar sobre as diferenças. Porto Alegre: Editora Mediações, 1998.

PERLIN, Gladis. Surdos: fissuras no contemporâneo. In: COELHO, O. ; KLEIN, M. (Org.). Cartografias da surdez: Comunidade, línguas, práticas e pedagogia. Porto, Portugal: Editora Livpsic, 2013.

THIESEN, Joares da Silva. A Internacionalização dos currículos na Educação Básica: concepções e conceitos. Revista e-curriculum, São Paulo, v. 15, n 4, p.911-2017 outb/dez, 2017. Disponível em: http://revistas.pucsp.br/index.php/curriculum. Acesso em: 1 jan. 2018.

UNESCO. Declaração de Salamanca sobre Princípios, Política e Práticas na Area das Necessidades Educativas Especiais, 1994. Disponível em:

https://unesdoc.unesco.org/ark:/48223/pf0000139394 Acesso em: 10 jul. 2018.

VAZ, Henrique. As escolas de referência para surdos: quando a língua se configura como meio tradutor, discute-se cidadania. In: COELHO, O.; KLEIN, M. (Org). Cartografias da surdez: Comunidade, línguas, práticas e pedagogia. Porto, Portugal: Editora Livpsic, 2013.

\section{Notas}

1 Trata-se de uma investigação de doutoramento em desenvolvimento na FPCEUP da Universidade do Porto, Portugal.

${ }^{2}$ É justamente essa concepção sócio-antropológica que dá origem à educação bilíngue.

\section{Correspondência}

Veronica Lima da Fonseca Almeida - Instituto Federal de Brasília, Quadra 610 Módulos D, E, F, G - Asa Norte, Brasília, Distrito Federal - Brasil.

CEP: $70830-450$

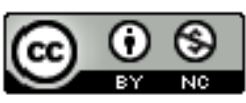

This work is licensed under a Creative Commons Attribution-NonCommercial 4.0 International (CC BY-NC 4.0) 